\title{
Characterization of Microscopic Pore Structures of Rock Salt through Mercury Injection and Nitrogen Absorption Tests
}

\author{
Jianwen Chen, ${ }^{1}$ Erbing $\mathrm{Li}^{2}{ }^{2}$ and Jin Luo $\mathbb{D}^{1,3}$ \\ ${ }^{1}$ Faculty of Engineering, China University of Geosciences (Wuhan), Wuhan 430074, China \\ ${ }^{2}$ College of Defense Engineering, Army Engineering University of PLA, Nanjing 210007, China \\ ${ }^{3}$ Department of Civil and Environmental Engineering, University of California, Berkeley, Berkeley, CA 94720, USA
}

Correspondence should be addressed to Jin Luo; jinluo@cug.edu.cn

Received 5 March 2018; Accepted 12 April 2018; Published 15 May 2018

Academic Editor: Liangping Li

Copyright (C) 2018 Jianwen Chen et al. This is an open access article distributed under the Creative Commons Attribution License, which permits unrestricted use, distribution, and reproduction in any medium, provided the original work is properly cited.

\begin{abstract}
Microscopic pore structure of rock salt plays a dominant role in its permeability. In this paper, microscopic pore structure of a set of rock salt samples collected from Yunying salt mine of Hubei province in China is investigated by high pressure mercury injection, rate-controlled mercury penetration, and nitrogen absorption tests. The pore size distribution is further evaluated based on fractal analysis. The results show that pore size of rock salt varies from 0.01 to $300 \mu \mathrm{m}$ with major concentration of pore size smaller than $1.00 \mu \mathrm{m}$. The pore's radiuses are mainly distributed within a range between 15 and $50 \mathrm{~nm}$. The research further reveals that the pore channel size of rock salt is randomly distributed, but the distribution of pore throat radius fits very well with fractal law. By analysis of permeability, it is found that the maximum and medium radius of the pore throat have significant impacts on permeability. Porosity is not apparently related to the permeability of rock salt. The higher the fractal dimension is, the higher the impacts on permeability of the small throat are detected and the lower the influence on permeability of the big throat is exhibited. It indicates that the small throat determines majorly the permeability of rock salt. The findings obtained from this study provide an insight into understanding the characteristics of microscopic pore structure of rock salt.
\end{abstract}

\section{Introduction}

Rock salt is an ideal underground medium to store energy (oil and natural gas) with $90 \%$ of the world's energy repository constructed in rock salt medium or deserted salt mines $[1,2]$. The first rock salt natural gas repository went into operation in Jintan, Jiangsu Province, in 2007, and there will be more rock salt gas repository going into operation to address the cyclic operation needs of natural gas. Although rock salt gas repository is relatively safe, it is still possible that natural gas could leak from salt caverns and thus cause explosion accidents [3]. According to [4], till 2009, the rate for rock salt gas repository accidents was $11 \%$ worldwide, with $60 \%$ of the accidents causing blowout explosion disasters resulting from failure of gas repository leakproofness. Only with great leakproofness of salt caverns can natural gas in rock salt gas repository be prevented from leaking and pore structure of rock salt is the key element to evaluate the leakproofness of rock salt $[5,6]$
As a polycrystalline polymer, rock salt features great leakproofness with a porosity rate of less than $0.5 \%$ for undisturbed rock salt and a permeability rate of $10^{-21}-10^{-20} \mathrm{~m}^{2}$ [7]. However, rock salt dilatancy behavior will lead to remarkable increase in permeability rate. For instance, with a dilatancy rate of $0.1-0.2 \%$, rock salt's permeability rate would increase by 4 to 5 orders of magnitude [8], indicating the interrelation between porosity rate and permeability rate $[9,10]$ and that study of pore structure is a significant aspect for the research of rock salt permeability. Cuevas [11] adopted mercury intrusion method, gas adsorption, and saturated hydrocarbon to test the pore structure of Cardona Saline Fm rock salt and divided rock salt pores into mesoscopic pores, microscopic pores, and macroscopic pores. Wu et al. [12] found that, with a porosity rate of $0.3-3.0 \%$, the permeability rate would be about $10^{-20} \mathrm{~m}^{2}$. Ji et al. [13] employed mercury intrusion method to test the average porosity rate of rock salt in Qianjiang, China, and found it to be $2.7 \%$. 


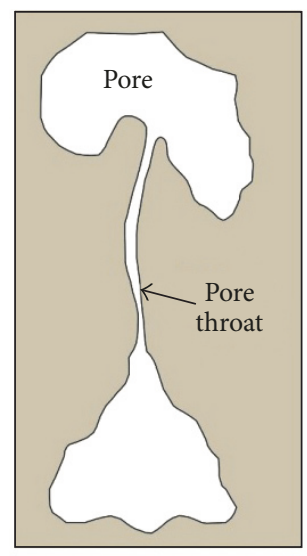

(a)

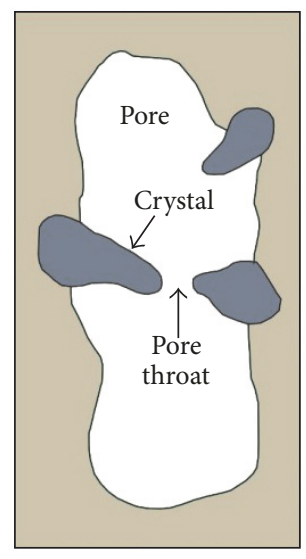

(b)

FIGURE 1: A sketch diagram of pore and pore throat in rock salt. (a) demonstrates two pores connecting with a pore throat; (b) displays a pore throat within a single pore.

Gueguen and Dienes [14] did some theoretical research into the relationship between rock microfracture and permeability rate based on statistics and percolation theory. Spangenberg et al. [15] made artificial rock salt with a porosity rate of 5-42\% and results show apparent relationship between permeability and porosity rates in samples. Afterwards, Popp and Kern [16], Popp et al. [17], Kissling [18], and Hampel and Schulze [19] consecutively tested the porosity and permeability rates of undisturbed rock salt and results show that there is certain relationship between porosity rate and permeability rate of rock salt and moreover, based on this, Lebensohn et al. [20] set up the gas permeation equation for rock salt.

However, Stormont and Daemen [21] experimented on the relationship between porosity and permeability rates in rock salt's force process and results show that permeability rate increases with the increase of porosity rate, but when confining pressure reaches $7.6 \mathrm{MPa}$, the increase of permeability rate with porosity rate is no longer apparent. Ji et al. [13] used mercury intrusion experiment to test rock salt in Qianjiang and found that there could be highly porous rock salt with low permeability rate. Therefore, the relationship between rock salt's permeability and porosity rates is very complicated. Apart from porosity rate, pore's channel, throat, connectivity between pores, and other structural features also have great influence on permeability rate, as a schematic diagram shown in Figure 1.

In order to better understand the influences of pore structure on permeability of rock salt, the present research implements mercury intrusion and gas adsorption testing methods to test the pore structure of rock salt in Yunying mine of China and analyze the porosity rate of rock salt, average pore throat ratio, average pore radius, size of pore, and the influence distribution geometry has on permeability rate so as to provide physical basis for the research on permeability rate.

\section{Sampling and Testing}

2.1. Sampling. The rock salt samples are collected from Yunying salt mine of Hubei province in China. Surface of samples are first cleaned and cut to be cubically shaped with size of $8 \times 8 \times 8 \mathrm{~mm}^{3}$. Then, the samples are covered perfectly using ethyl alcohol. Ten samples are grouped into two categories: group one contains Samples No. 1-No. 4 being tested by deploying high pressure injection and group two includes Samples No. 5-No. 10 being examined by rate-controlled penetration. The principle and testing setups mercury injection method is showed in Cuevas [11] and Zhu et al. [22]. Furthermore, the other four samples XF-01, $\mathrm{XF}-02, \mathrm{XF}-03$, and XF-04 are tested by nitrogen absorption method. The detailed process of this test has been reported in [23]. All tests are carried out using NOVA multifunctionphysical adsorption analyzer in the Geological Engineering Experiment Center, China University of Geosciences (Wuhan).

2.2. Testing Process. The setup of mercury injection test is organized as follows:

(i) Dry the samples by putting samples in vacuum oven with the temperature $80^{\circ} \mathrm{C}$ lasting for 4 hours; weigh the sample when this process is completed.

(ii) Open nitrogen pressure relief valve and set the outlet pressure of $0.28 \mathrm{MPa}$ and then open vacuum pump to start test, and simultaneously switch on the data logging system.

(iii) Put samples into NOVA to start first with low pressure test; then test the samples with deploying high pressure; the parameters including the accumulative volume of the mercury, mercury rate, and porosity are automatically recorded.

(iv) Shut down testing facilities and take the samples out of the devices.

The nitrogen absorption tests are set as follows: put samples into vacuum drying oven at $150^{\circ} \mathrm{C}$ and they are vacuumed for 10 hours and then put the samples into device NOVA to determine the adsorption-desorption curve. 
TABLE 1: Classification of the pore size of rock salt.

\begin{tabular}{|c|c|c|c|c|}
\hline Sample number & $\begin{array}{c}\text { Total porosity } \\
(\%)\end{array}$ & $\begin{array}{c}\text { Macroporosity } \\
(\%)\end{array}$ & $\begin{array}{c}\text { microporosity } \\
(\%)\end{array}$ & $\begin{array}{c}\text { Subporosity } \\
(\%)\end{array}$ \\
\hline No. 1 & 3.0660 & $18.90 \%$ & $22.56 \%$ & $58.54 \%$ \\
\hline No. 2 & 0.9900 & $15.98 \%$ & $26.32 \%$ & $57.64 \%$ \\
\hline No. 3 & 2.4099 & $16.70 \%$ & $25.10 \%$ & $58.20 \%$ \\
\hline No. 4 & 2.9468 & $10.81 \%$ & $37.06 \%$ & $53.04 \%$ \\
\hline No. 5 & 0.9343 & $51.74 \%$ & $12.17 \%$ & $86.09 \%$ \\
\hline No. 6 & 0.9526 & $0 \%$ & $30.52 \%$ & $63.48 \%$ \\
\hline No. 7 & 3.743 & $10.56 \%$ & $29.18 \%$ & $60.26 \%$ \\
\hline No. 8 & 0.4742 & $52.73 \%$ & $18.18 \%$ & $29.09 \%$ \\
\hline No. 9 & 0.5526 & $10.4 \%$ & $28.64 \%$ & $61.22 \%$ \\
\hline No. 10 & 0.6339 & $8.46 \%$ & $21.18 \%$ & $70.36 \%$ \\
\hline
\end{tabular}

TABLE 2: Porosity and the average throat radius.

\begin{tabular}{lccccr}
\hline Sample number & No. 5 & No. 6 & No. 7 & No. 8 & No. 9 \\
\hline $\begin{array}{l}\text { Porosity } \\
(\%)\end{array}$ & 0.9343 & 0.9526 & 3.743 & 0.4742 & 0.5526 \\
$\begin{array}{l}\text { Average throat } \\
\begin{array}{l}\text { radius } \\
(\mu \mathrm{m})\end{array}\end{array}$ & 0.0155 & 0.0143 & 0.0141 & 0.0169 & 0.6339 \\
\hline
\end{tabular}

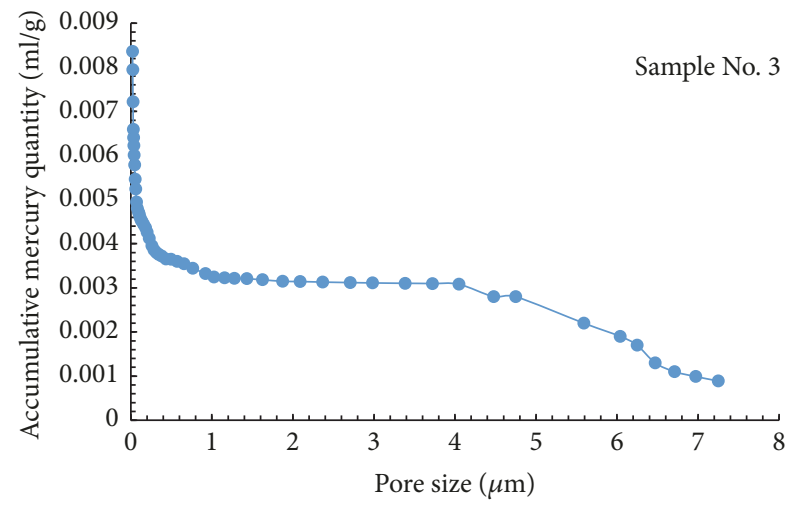

FIGURE 2: Accumulative mercury quantity versus pore size curve of Sample No. 3.

\section{Results and Discussion}

\subsection{Pore of Rock Salt}

3.1.1. Pore Size Distribution. The pore size distribution of the rock salt is determined based on high pressure mercury injection tests. Figure 2 shows the accumulative mercury quantity varies with pore size of Sample No. 3. According to previous studies $[24,25]$, the pore size of rock salt can be classified into three categories as follows: macroscopic pore with size larger than $8 \mu \mathrm{m}$, microscopic pore with a size varying between $1 \mu \mathrm{m}$ and $8 \mu \mathrm{m}$, and subpore with pore size that is smaller than $1.0 \mu \mathrm{m}$. Among these three types of pore, macroscopic pore is generally flat-shaped, the microscopic pores form often network, and subpore is connected as pore throat, as displayed in Figure 1.
The testing results show that the porosity of the rock salt samples collected from Yuying mine varies between $0.26 \%$ and $3.0 \%$, as shown in Table 1 . These findings fit very well with the results reported by $\mathrm{Wu}$ et al. [12]. On the other hand, the pore size is determined to be ranged from 2.0 to $300 \mu \mathrm{m}$. And the subpore accounts for $60 \%$ of the total pores in the samples. The curve of mercury injection pressure-increase mercury rate shows a singlet, indicating that the pore size is intensively concentrated. Furthermore, the pore size was determined to be concentrated within $15 \mathrm{~nm}$ to $35 \mathrm{~nm}$, implying a subpore dominated porous mediums of the rock salt.

3.1.2. Pore Throat Radius. Both pore volume and pore throat volume can be precisely determined by rate-controlled penetration experiments. Thus, the pore structure is investigated very specifically. In this study, six samples including Nos. 5-10 are tested by rate-controlled penetration experiment. Table 2 lists the determined porosity and the average throat radius of the samples. The average throat radius varies from $14 \mathrm{~nm}$ to $18 \mathrm{~nm}$ based on this method; it is verified that the pores majorly consist of subpores.

Considering that nitrogen absorption experiment can test the pore size from $0.35 \mathrm{~nm}$ to $100 \mathrm{~nm}$ and the ratecontrolled penetration test can test pore size ranging from $7 \mathrm{~nm}$ to $200 \mu \mathrm{m}$, the nitrogen absorption experiment is applied to investigate the pore size characteristics in the present study. Three samples are prepared and tested and the obtained results are listed in Table 3 . The throat radiuses for these samples are $6.04 \mathrm{~nm}, 13.54 \mathrm{~nm}$, and $38.07 \mathrm{~nm}$, with void volume per weight being $80 \mathrm{~cm}^{3} \mathrm{~g}^{-1}, 100 \mathrm{~cm}^{3} \mathrm{~g}^{-1}$, and $1400 \mathrm{~cm}^{3} / \mathrm{g}^{-1}$, respectively.

By analysis, the samples XF-02, XF-03, and XF-04 exhibit obviously peaks in their BJH (Barrett Joyner and Halenda) 
TABLE 3: The determined specific surface area and pore size using nitrogen absorption method.

\begin{tabular}{lccc}
\hline Sample number & XF-01 & XF-02 & XF-03 \\
\hline Average pore throat radius $(\mathrm{nm})$ & 6.04 & 13.54 & 38.07 \\
Specific surface area $\left(\mathrm{m}^{2} \mathrm{~g}^{-1}\right)$ & $13.3 \times 10^{3}$ & $7.16 \times 10^{3}$ & $0.3 \times 10^{3}$ \\
Micropore volume $\left(\mathrm{cm}^{3} \mathrm{~g}^{-1}\right)$ & 80 & 100 & 1400 \\
\hline
\end{tabular}

TABLE 4: Major parameters for the distribution of pore throat.

\begin{tabular}{|c|c|c|c|c|c|c|}
\hline Sample number & No. 5 & No. 6 & No. 7 & No. 8 & No. 9 & No. 10 \\
\hline Average throat radius $(\mu \mathrm{m})$ & 0.0155 & 0.0143 & 0.0141 & 0.0169 & 0.0168 & 0.0185 \\
\hline Sorting coefficient & 0.5802 & 0.6187 & 0.7113 & 0.5537 & 0.9104 & 0.6979 \\
\hline Fractal dimension $(D,-)$ & 2.47 & 2.38 & 2.53 & 2.23 & 2.19 & 2.62 \\
\hline Fractal coefficient $(a,-)$ & 4.086 & 22.420 & 11.821 & 16.900 & 11.900 & 9.071 \\
\hline Relation coefficient $\left(R^{2},-\right)$ & 0.997 & 0.955 & 0.995 & 0.874 & 0.932 & 0.985 \\
\hline
\end{tabular}

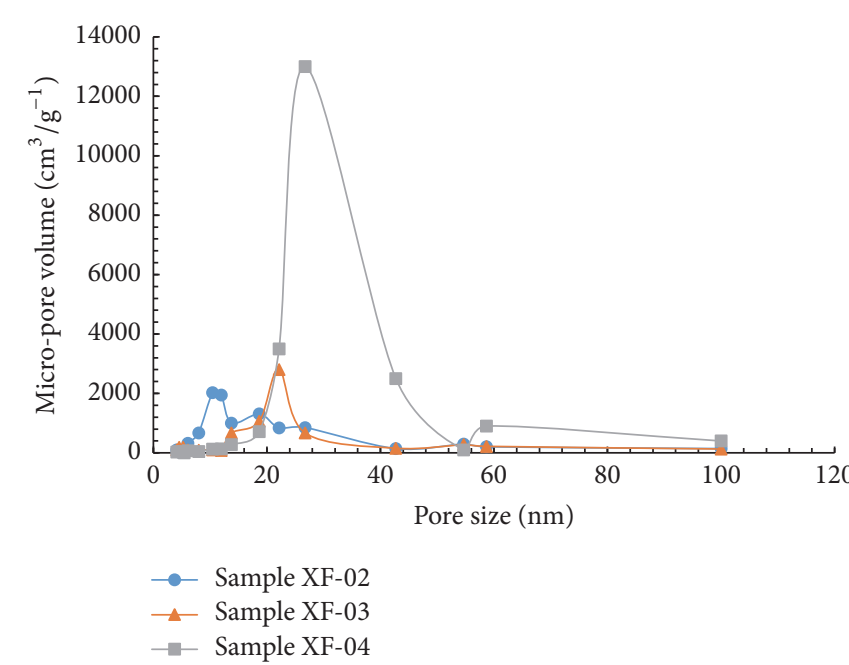

FIGURE 3: The BJH distribution of pore size of the rock salt samples.

distribution curve, as shown in Figure 3. The corresponding pore sizes to the peak values are $10.4 \mathrm{~nm}, 22.1 \mathrm{~nm}$, and $26.7 \mathrm{~nm}$, showing that the pore sizes are mainly distributed among $10 \mathrm{~nm}$ and $30 \mathrm{~nm}$.

3.1.3. The Pore Size Distribution of Channel and Pore Throat. Figure 4 shows the pores channels and pore throats determined by rate-controlled penetration test. It can be seen that the pore throats are mainly concentrated with the size smaller than $2.0 \mu \mathrm{m}$. By fitting the curve, it is found that the distribution of pore exhibits an exponential relationship with quantity of the pores percentage.

The study above revealed that the pore throats have a size generally smaller than $2.0 \mu \mathrm{m}$. According to fractal theory [26], the number of pore throats can be derived as follows in case of the distribution of pore throat fit with fractal theory:

$$
N(r)=a r^{-D} \text {. }
$$

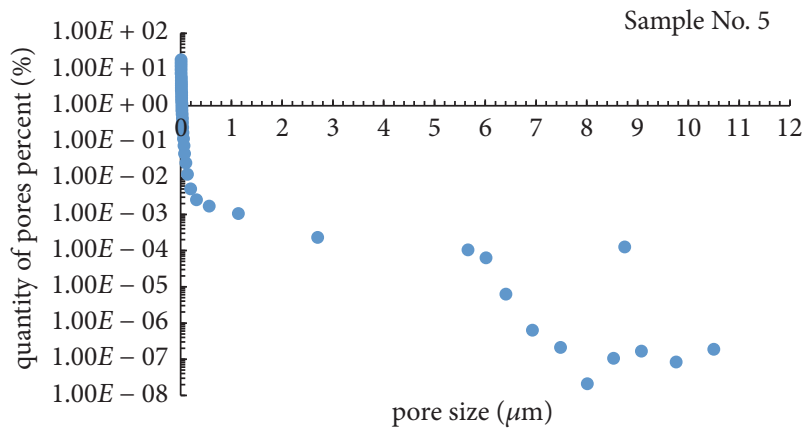

FIgURE 4: The pore size distribution of Sample No. 3.

Similarly, the function for the distribution of pore throat can be formulated as follows:

$$
P(r)=a D r^{-D-1},
$$

where $N$ is quantity of pore throat; $P(r)$ is the function on pore throat radius density distribution; $r$ is the pore throat radius, in $\mu \mathrm{m}$; $a$ is the fractal coefficient; and $D$ is the fractal dimension of the pore throat distribution.

Taking Samples No. 5-No. 10, for example, the pore channels are analyzed by following fractal theory for the size both smaller and bigger than $2.0 \mu \mathrm{m}$. Table 4 shows the results for the pore channel. The fractal dimensions of these six samples are varied between 2.19 to 2.62 with correlation coefficient of 0.874-0.997. According to the fractal theory, the three-dimensional pore should range from 2.0 to 3.0. The finding indicates that the pore channel distribution fits very well with the fractal theory. Therefore, the microscopic structure of the pore throat can be quantitatively estimated by fractal dimensions.

On the other hand, pore channel is also analyzed using the fractal dimensions, as shown in Table 5. The fractal dimensions are determined to be ranged from 3.75 to 6.29 , implying that the distribution of pore channel does not fit the fractal law. 
TABLE 5: The pore channel distribution and fractal dimensions.

\begin{tabular}{lcccccc}
\hline Sample number & No. 5 & No. 6 & No. 7 & No. 8 & No. 9 & No. 10 \\
\hline Fractal dimension $D$ & 6.29 & 3.75 & 6.04 & 4.54 & 4.87 & 5.95 \\
Fractal coefficient $a$ & 19.00 & 8.50 & 6.90 & 6.84 & 8.40 & 12.30 \\
Relation coefficient $R^{2}$ & 0.451 & 0.684 & 0.705 & 0.948 & 0.922 & 0.811 \\
\hline
\end{tabular}

TABLE 6: Relationship of throat microgeometrical parameters with porosity and permeability.

\begin{tabular}{|c|c|c|c|c|}
\hline $\begin{array}{l}\text { Microgeometrical } \\
\text { parameters }\end{array}$ & Maximum & Minimum & $\begin{array}{l}\text { Correlation with } \\
\text { porosity }\end{array}$ & $\begin{array}{l}\text { Correlation with } \\
\text { permeability }\end{array}$ \\
\hline Skewness & 1.08 & 0.39 & $\begin{array}{c}y=0.831 x^{-1.18} \\
R^{2}=0.382\end{array}$ & $\begin{array}{c}y=0.008 x^{-0.97} \\
R^{2}=0.136\end{array}$ \\
\hline Sorting coefficient & 1.3449 & 0.3023 & $\begin{array}{c}y=1.374 x^{0.233} \\
R^{2}=0.017\end{array}$ & $\begin{array}{c}y=0.005 x^{1.648} \\
R^{2}=0.139\end{array}$ \\
\hline $\begin{array}{l}\text { Variation } \\
\text { coefficient }\end{array}$ & 0.797 & 0.5006 & $\begin{array}{c}y=3.462 x^{1.978} \\
R^{2}=0.166\end{array}$ & $\begin{array}{c}y=0.501 x^{9.991} \\
R^{2}=0.663\end{array}$ \\
\hline $\begin{array}{l}\text { Median pore throat } \\
\text { radius } \\
(\mu \mathrm{m})\end{array}$ & 1.115 & 0.0086 & $\begin{array}{c}y=1.647 x^{0.192} \\
R^{2}=0.136\end{array}$ & $\begin{array}{c}y=0.015 x^{1.106} \\
R^{2}=0.775\end{array}$ \\
\hline $\begin{array}{l}\text { Median pressure } \\
(\mathrm{MPa})\end{array}$ & 36.293 & 0.3871 & $\begin{array}{c}y=3.552 x^{-0.53} \\
R^{2}=0.739\end{array}$ & $\begin{array}{c}y=0.028 x^{-0.46} \\
R^{2}=0.400\end{array}$ \\
\hline $\begin{array}{l}\text { Displacement } \\
\text { pressure }(\mathrm{MPa})\end{array}$ & 0.07176 & 0.0471 & $\begin{array}{c}y=3.458 x^{0.796} \\
R^{2}=0.715\end{array}$ & $\begin{array}{c}y=0.022 x^{0.749} \\
R^{2}=0.837\end{array}$ \\
\hline $\begin{array}{l}\text { Maximum } \\
\text { mercury saturation } \\
(\%)\end{array}$ & 96.04 & 71.43 & $\begin{array}{c}y=5 \mathrm{E}-10 x^{4.919} \\
R^{2}=0.722\end{array}$ & $\begin{array}{c}y=9 \mathrm{E}-16 x^{6.792} \\
R^{2}=0.540\end{array}$ \\
\hline
\end{tabular}

3.2. Relationship of Throat Microgeometrical Parameters with Porosity and Permeability. Pore throat reveals the connection among the pores which is considered to be crucially important to the permeability of rock mass. The parameters including average capillary pressure, $P_{d}$, the displacement pressure, the median pressure, $P_{\mathrm{C} 50}$, the mean capillary pressure, $\overline{p_{c}}$, mean value, $\bar{X}$, sorting coefficient, $\sigma$, variation coefficient, $\mathrm{vc}$, and skewness, $S_{k}$, can be determined by mercury injection test. These parameters are useful in quantitatively determining the pore's structure. Among all the parameters, $S_{k}$ represents the distribution of pore throat radius.

Ten samples are tested by the capillary tests and the obtained parameters are displayed in Table 6. It shows that $P_{d}, P_{c 50}$ and the maximum mercury saturation have good correlation with porosity of the rock salt. $P_{d}$ represents the minimum pressure for the mercury entering into the pores, corresponding to the maximum pore throat radius. Similarly, $P_{\mathrm{C} 50}$ denotes the median pressure that is accordance with the median radius. In general, the bigger the pore size is the lower displacement pressure is. The maximum mercury saturation represents a peak pressure for the injection test. The larger the volume of mercury entering the pore means the better the connectivity of the pores, and the higher the porosity detected.

Table 6 shows that the displacement pressure, $P_{d}$, and median pressure are strongly related to porosity of rock salt, with the correlation coefficient $R^{2}=0.837$ and $R^{2}=$ 0.775 . In addition, the variation coefficients show a weak correlation with porosity, $R^{2}=0.166$. A low correlation

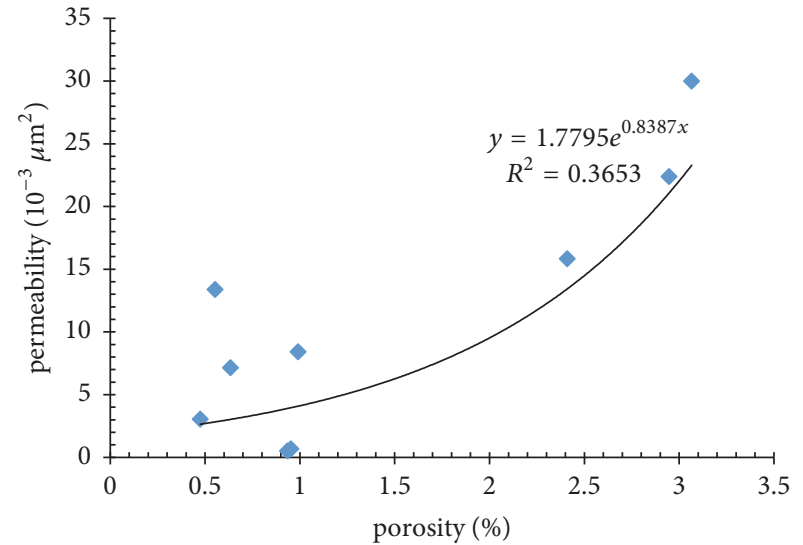

FIGURE 5: Relationship between porosity and permeability of rock salt.

coefficient is shown when fitting porosity with permeability, as it is also verified in Figure 5. Therefore, the porosity has no obvious effects on permeability of the rock salt. Conclusively, the microstructures of the pore throat such as shape, size, connectivity, and distribution are the important factors to the permeability of the rock salt

3.3. Influences of Pore Throat on Permeability. The low permeable medium has generally small throat radius, but with big pore size. The throat has larger number than pore and thus the throat plays determining role in the permeability of rock salt [27]. As this study revealed above that distribution 


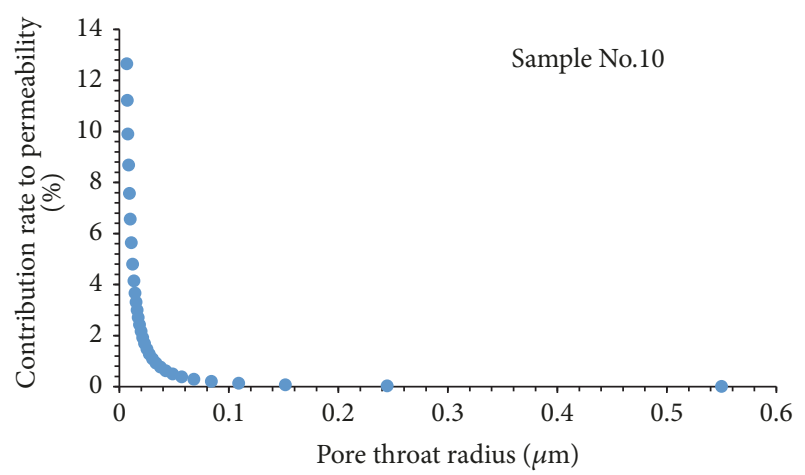

FIgURE 6: Pore throat radius and its contribution rate to permeability.

of pore size conforms very well with fractal theory. According to Hagen-Poiseuille's approach, the contribution of a single throat to permeability can be formulated as follows:

$$
\Delta K_{i}=\frac{r_{i}^{1-D}}{\sum_{i=1}^{n} r_{i}^{1-D}},
$$

where $\Delta K_{i}$ is the contribution rate to permeability of a single pore throat radius; $r$ represents the radius $(\mu \mathrm{m})$.

Figure 6 shows that pore throat radius versus with contribution rate to permeability of rock salt Sample No. 10. It is observed that the small pore throat contributes mainly the permeability. The effect of throat radius on permeability becomes negligible when the radius is larger than $0.1 \mu \mathrm{m}$.

\section{Conclusions}

In this paper, the microscopic pore structure and its influences on permeability of rock salt samples collected from Yunying salt mine in China are studied. High pressure mercury injection, rate-controlled mercury penetration, and nitrogen absorption experiments are carried out to determine the pore size and its distribution. The impact of pore size and structure on permeability is then analyzed. Major findings of this study include the following:

(i) The porosity of rock salt is determined to be varying between $0.26 \%$ and $3.00 \%$. The pore size covers a range from 0.01 to $300 \mu \mathrm{m}$, which can be categorized into macroscopic pore with pore size larger than $8 \mu \mathrm{m}$, microscopic pore $(1 \mu \mathrm{m}-8 \mu \mathrm{m})$, and subpore $(<1 \mu \mathrm{m})$. The void of rock salt mainly consists of subpore, accounting for $60 \%$ of the total pores. The pore size is estimated to range mainly from $15 \mathrm{~nm}$ to $50 \mathrm{~nm}$ based on Wash-Born approach. The pore throat radius is determined to be within $10 \mathrm{~nm}$ to $30 \mathrm{~nm}$ by nitrogen absorption tests.

(ii) Pore channel size of the rock salt is distributed randomly, but the pore throat radius conforms with the law of fractal theory and the fractal dimension is determined to vary between 2.19 and 2.62. The displacement pressure, $P_{d}$, the median pressure, $\mathrm{P}_{C 50}$, and the maximum mercury saturation are found to be strongly correlated with porosity.

(iii) The porosity of the rock salt is observed to be not correlated obviously with its permeability. On the other hand, maximum pore and median pore throat radius are both related to permeability of the rock salt. The variation coefficient of pore throat distribution is estimated to be 0.663 , indicating they are strongly correlated. Thus, pore throat radius plays dominated role in permeability of rock salt. The further research shows that the influences of big throat radius on permeability of rock salt become lower and the contribution of small throat radius on permeability increases drastically with increasing the fractal dimension.

\section{Data Availability}

The data used to support the findings of this study are available from the corresponding author upon request.

\section{Conflicts of Interest}

The authors declare that they have no conflicts of interest.

\section{Acknowledgments}

The project was also supported by the National Natural Science Foundation of China (no. 51474259) and Fundamental Research Funds for the Central Universities, China University of Geosciences (Wuhan) no. CUGL150818 and no. CUGL 150610. The funding provided by China Scholarship Council (CSC) during the visit at University of California, Berkeley, is deeply appreciated.

\section{References}

[1] C. H. Yang, W. G. Liang, D. H. Wei et al., "Investigation on possibility of energy storage in salt rock in China," Chinese Journal of Rock Mechanics and Engineering, vol. 24, no. 24, pp. 4409-4417, 2005.

[2] J. Cai, B. Yu, M. Zou, and L. Luo, "Fractal characterization of spontaneous co-current imbibition in porous media," Energy \& Fuels, vol. 24, no. 3, pp. 1860-1867, 2010.

[3] M. Zhang and M. J. McSaveney, "Rock avalanche deposits store quantitative evidence on internal shear during runout," Geophysical Research Letters, vol. 44, no. 17, pp. 8814-8821, 2017.

[4] L. H. Xie, H. L. Li, X. W. Zhao et al., "Statistics and risk analysis of underground gas storage accident in salt caverns," China Safety Science Journal, vol. 19, no. 9, pp. 125-132, 2009.

[5] S. Wang, X. Han, Y. Dong, and H. Shi, "Mechanisms of reservoir pore/throat characteristics evolution during longterm waterflooding," Advances in Geo-Energy Research, vol. 1, no. 3, pp. 148-157, 2017.

[6] Y. Xia, J. Cai, W. Wei, X. Hu, X. Wang, and X. Ge, "A new method for calculating fractal dimensions of porous media based on pore size distribution," Fractals, vol. 26, no. 1, Article ID 1850006, 2018. 
[7] P. Berest, J. Bergues, B. Brouard et al., "A salt cavern abandonment test," International Journal of Rock Mechanics \& Mining Sciences, vol. 38, pp. 357-368, 2001.

[8] O. Schulze, T. Popp, and H. Kern, "Development of damage and permeability in deforming rock salt," Engineering Geology, vol. 61, no. 3, pp. 163-180, 2001.

[9] W. Liu, N. Muhammad, Y. Li, C. J. Spiers, C. Yang, and H. $\mathrm{Ma}$, "Experimental study of permeability of salt rock and its application to deep underground gas storage," Chinese Journal of Rock Mechanics and Engineering, vol. 33, no. 10, pp. 1953-1961, 2014.

[10] S. Huang, Y. Wu, X. Meng, L. Liu, and W. Ji, “Recent advances on microscopic pore characteristics of low permeability sandstone reservoirs," Advances in Geo-Energy Research, vol. 2, no. 2, pp. 122-134, 2018.

[11] C. D. L. Cuevas, "Pore structure characterization in rock salt," Engineering Geology, vol. 47, no. 1, pp. 17-30, 1997.

[12] Z. Wu, H. Zhou, J. Ding, L. Ran, and H. Yi, "Research on permeability testing of rock salt under different permeability pressures," Chinese Journal of Rock Mechanics and Engineering, vol. 31, no. S2, pp. 3740-3746, 2012.

[13] W. Ji, C. H. Yang, W. Liu, and M. Li, "Experimental investigation on meso-pore structure properties of bedded salt rock," Chinese Journal of Rock Mechanics and Engineering, vol. 32, no. 10, pp. 2036-2044, 2013.

[14] Y. Gueguen and J. Dienes, "Transport properties of rocks from statistics and percolation," Mathematical Geology, vol. 21, no. 1, pp. 1-13, 1989.

[15] E. Spangenberg, U. Spangenberg, and C. Heindorf, "An experimental study of transport properties of porous rock salt," Physics and Chemistry of the Earth, vol. 23, no. 3, pp. 367-371, 1998.

[16] T. Popp and H. Kern, "Monitoring the state of microfracturing in rock salt during deformation by combined measurements of permeability and P-and S-wave velocity," Physics and Chemistry Earth, vol. 25, no. 2, pp. 149-154, 2000.

[17] T. Popp, H. Kern, and O. Schulze, "Evolution of dilatancy and permeability in rock salt during hydrostatic compaction and triaxial deformation," Journal of Geophysics, vol. 106, no. B3, pp. 4061-4078, 2001.

[18] W. Kissling, "Transport of three-phase hyper-saline brines in porous media: theory and code complementation," Transport Porous Medium, vol. 61, pp. 25-44, 2005.

[19] A. Hampel and O. Schulze, "The composite dilatancy model: a constitutive model for the mechanical behavior of rock salt," in Proceedings of the 6th Conference on The Mechanical Behavior of Salt-Understanding of THMC Process in Salt, M. Wallner, K.-H. Lux, W. Minkley, and H. R. Hardy Jr., Eds., pp. 99-107, Taylor \& Francis Group, London, UK, 2007.

[20] R. A. Lebensohn, P. R. Dawson, H. M. Kern, and H.-R. Wenk, "Heterogeneous deformation and texture development in halite polycrystals: Comparison of different modeling approaches and experimental data," Tectonophysics, vol. 370, no. 1-4, pp. 287-311, 2003.

[21] J. C. Stormont and J. J. K. Daemen, "Laboratory study of gas permeability changes in rock salt during deformation," International Journal of Rock Mechanics and Mining Sciences \& Geomechanics Abstracts, vol. 29, no. 2, pp. 325-342, 1992.

[22] Y. X. Zhu, W. Sun, and Y. U. Feng, "Application of high pressure injection and rate-controlled penetration experimental technique to studying reservoir microscopic pore structure," Natural Gas Geoscience, vol. 19, no. 4, p. 553, 2008.
[23] T. X. Zhong, "Characteristics of pore structure of marine shales in South China," Natural Gas Industry, vol. 32, no. 9, pp. 1-4, 2012.

[24] H. H. Yuan and B. F. Swanson, "Resolving pore space characteristics by rate-controlled porosimetry," SPE Formation Evaluation, vol. 4, article no. 14892, no. 01, pp. 167-175, 1986.

[25] M. Zhang, Y. Yin, and R. Hu, "Mechanisms of rainfall-induced landslides in gently inclined red beds in the eastern Sichuan," Landslides, vol. 12, no. 5, pp. 973-983, 2015.

[26] B. B. Mandelbrot, Fractals: Form, Chance and Dimension, Freeman, San Francisco, Calif, USA, 1977.

[27] J. B. Yu, D. J. Guo, and X. Q. Wang, "Study of microscopic behavior of low permeable reservoir through constant velocity mercury injection technique," Journal of Daqing Petroleum Institute, vol. 30, no. 2, pp. 22-25, 2006. 

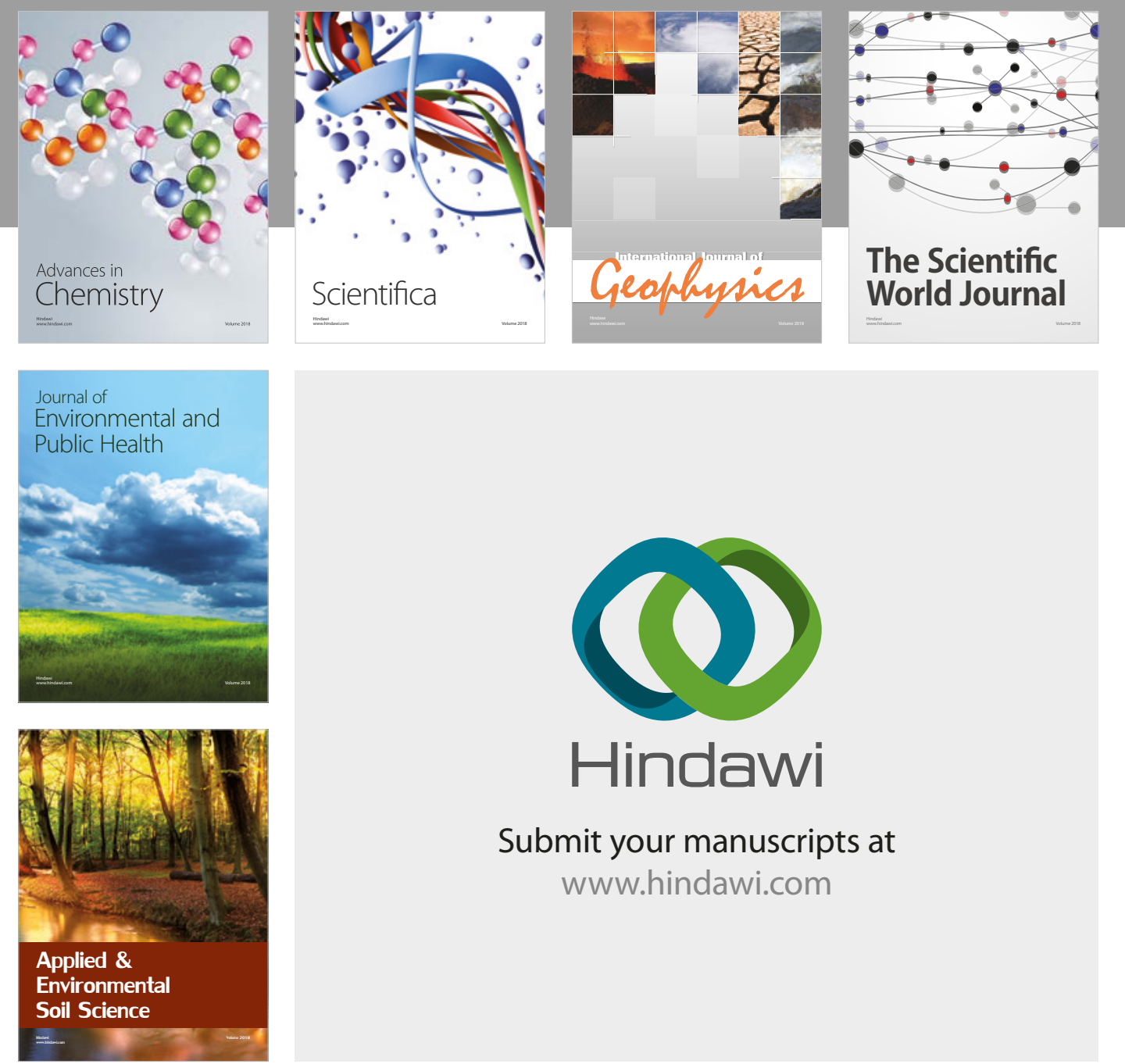

The Scientific

\section{World Journal}
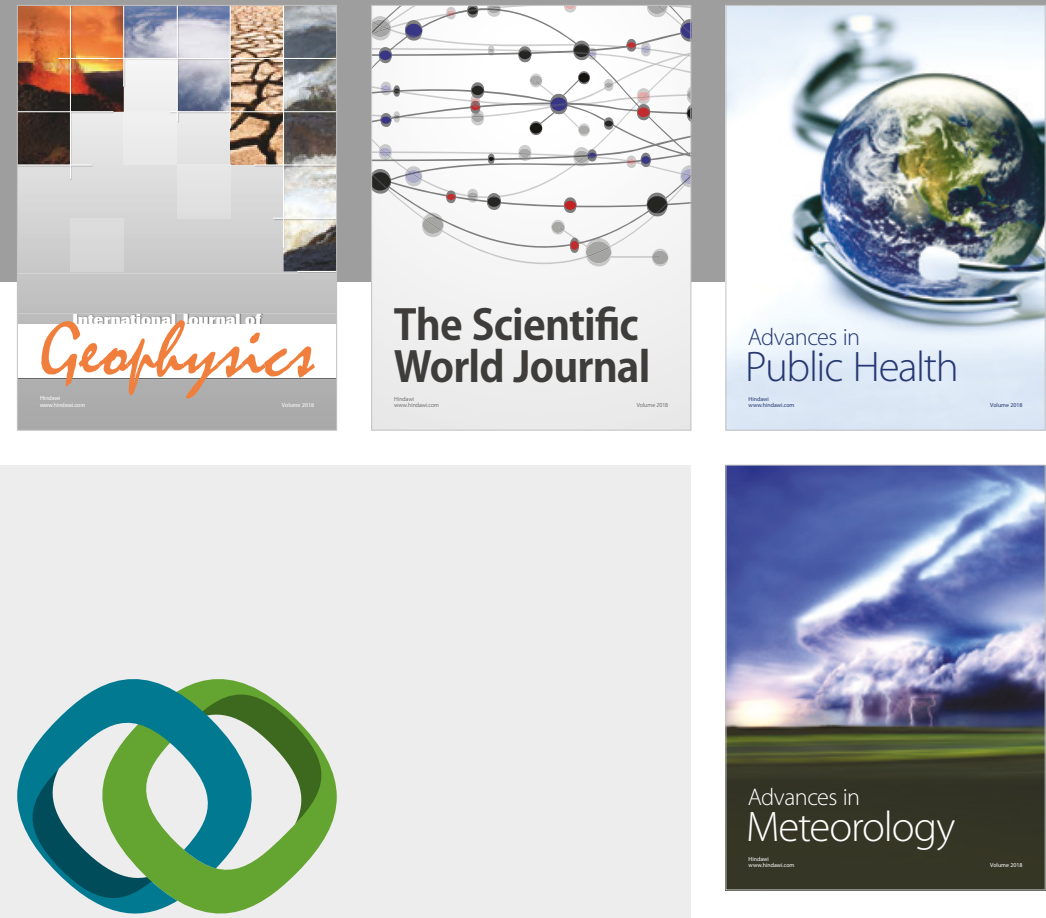

Advan

Public Health

\section{Hindawi}

Submit your manuscripts at

www.hindawi.com
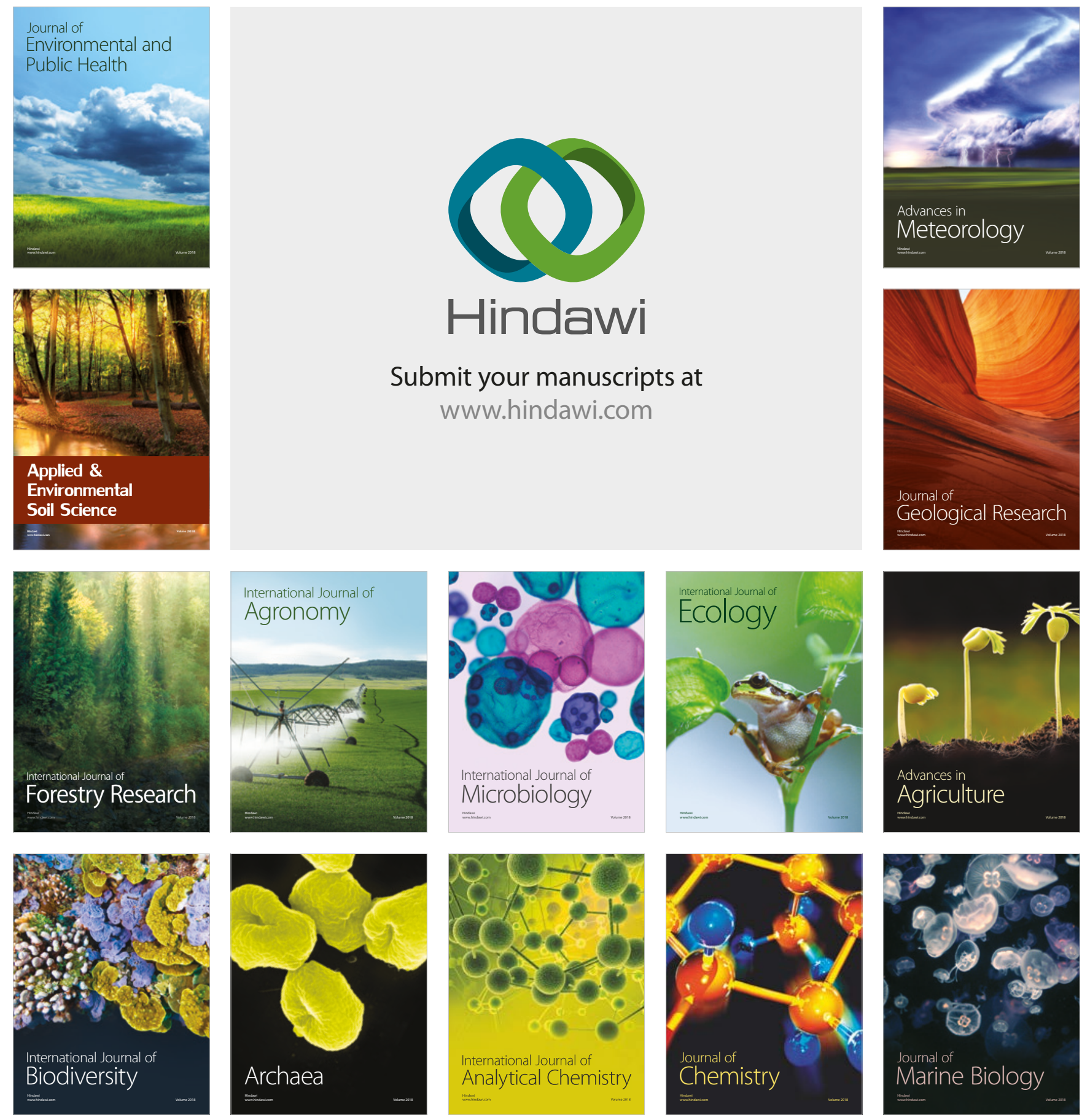